\title{
Self-perception of olfactory dysfunction is associated with history of Traumatic Brain Injury: post-hoc analysis from the OLFACAT survey*
}

\author{
Cristóbal Langdon 1,2,3, Isam Alobid 1,2,3, Llorenç Quintó4, Antonio Valero ${ }^{3,5}$, \\ Cèsar Picado ${ }^{3,5}$, Concepció Marin ${ }^{2,3}$, Joaquim Mullol 1,2,3 \\ ' Rhinology Unit and Smell Clinic, Department of Otorhinolaryngology, Hospital Clínic, Universitat de Barcelona, Barcelona, \\ Catalonia, Spain \\ 2 Sinonasal Inflammatory and Olfactory Research Group (INGENIO), IRCE, IDIBAPS, Barcelona, Catalonia, Spain \\ ${ }^{3}$ Centre for Biomedical Research on Respiratory Diseases (CIBERES), Spain \\ ${ }^{4}$ Institut de Salut Global de Barcelona (ISGlobal) de Recerca en Salut Internacional de Barcelona (CRESIB), Barcelona, Catalonia, \\ Spain \\ ${ }^{5}$ Allergy Section, Department of Pneumology and Allergy, Hospital Clínic, Universitat de Barcelona, Barcelona, Catalonia, Spain
}

Rhinology 57: 6, $460-468,2019$

https://doi.org/10.4193/Rhin18.295

*Received for publication:

December 19, 2018

Accepted: July 5, 2019

\begin{abstract}
Background: Traumatic brain injury (TBI) is one of the main causes of smell loss. However, epidemiological studies evaluating the incidence in general population are scarce. The aim of this analysis is to investigate the prevalence of TBI-induced olfactory dysfunction (OD) in a general-based population study.
\end{abstract}

Methodology: A cross-sectional population-based survey was distributed to general population ( 260,000 households) through the newspaper. The survey included four microencapsulated odorants (smell test) to assess smell loss and two self-administered questionnaires (odour description and epidemiology/health status). Participants were divided into two groups, with or without a history of TBI.

Results: From 10,783 returned surveys, 9,348 were analysed. The survey profile was a 43-year old woman with medium-high educational level, living in a city. The overall prevalence of TBI was $5 \%$ ( $N=464,44.5 \pm 14.1$ years old, $57 \%$ females). Recorded causes of TBI were traffic, domestic, or work accidents. Subjects with TBI reported a poorer subjective smell self-perception compared to non-TBI participants, and a decreases ability to identify mercaptan (odour added to gas used in cities). Although, using the smell test, both groups showed similar smell capacities.

Conclusions: Subjects with TBI history report a higher frequency of self-perceived OD, and a decrease ability to smell the odour added to domestic gas. Having said that, the prevalence of $\mathrm{OD}$, according to the smell test, was similar in both groups.

Key words: smell disorders, anosmia, hyposmia, traumatic brain injury, olfactory dysfunction

\section{Introduction}

Traumatic brain injury (TBI) constitutes a major health and socioeconomic problem (1). TBI is defined as the damage to the brain caused by external mechanical force, in which the brain function is temporarily, or permanently impaired and structural damage may or may not be detectable with current technology ${ }^{(2)}$. Epidemiological data on TBI from the European Union estimated an annual incidence for hospitalised and fatal TBI of approximately 235 per 100,000 inhabitants ${ }^{(3)}$. Usually, patients with TBI have residual deficits that impact their quality of life ${ }^{(4)}$.

Prevalence and risk factors for olfactory impairment in European population studies have been scarcely investigated. Additionally, only a few epidemiological studies, using psychophysical testing methods ${ }^{(5)}$ or self-administered microencapsulated 
smell test ${ }^{(6)}$, have assessed the impact of TBI in olfactory function as a secondary objective. In the OLFACAT (Olfaction in Catalonia) survey, the authors reported that participants with a history of head trauma had a higher risk of identification anosmia. Olfactory dysfunction (OD) is considered to be one of the "silent" problems of TBI. This is due to the fact that usually patients do not seek attention ${ }^{(7)}$. The incidence of OD following TBI varies across studies, ranging from as low as $12.8 \%{ }^{(8)}$ to as high as $87 \%{ }^{(9)}$. This variability may result from differences in the methods used to assess OD and the score level used to indicate the impairment ${ }^{(10,11)}$. A higher percentage of OD after TBI was observed in studies, analysing patients referred to rhinology centres complaining of smell loss. Costanzo et al. ${ }^{(12)}$ diagnosed anosmia in $60 \%$ of patients undergoing a previous TBI. This may be explained by the fact that most of the participants taking part in these studies are seeking for medical attention and, in consequence, most of the of patients may have been moderated to severe TBI. The association between TBI severity and the level of OD has been described ${ }^{(11,13)}$. Yet, it is also correct that reports of mild head injuries may produce a complete olfactory loss ${ }^{(14)}$. Consequently, most of the studies may under-report the number of people sustaining a mild head trauma, as those patients do not often get medical attention ${ }^{(15)}$.

Since epidemiological studies evaluating specifically the incidence of TBI-induced OD in general population are scarce, the aim of this study was to investigate the prevalence of association between OD and history of head trauma in a general-based population cohort (OLFACAT survey).

\section{Materials and methods}

Study population and design

This study was based on data collected in the OLFACAT (Olfaction in Catalonia) survey ${ }^{(6)}$. Assessment of olfaction with a set of four microencapsulated odorants, and demography - health status was based on two questionnaires. For the purpose of this study, the participants were divided into two groups with (TBI) or without (non-TBI) history of trauma brain history. The present manuscript has followed the STROBE checklist guidelines. The Institutional Ethics and Clinical Research Committee of Hospital Clínic Barcelona approved the study (Reference № HCP 2003/1295).

\section{Outcomes}

Survey odorants. Four common odorants were included in the survey: rose ( $2 \%$ of Bulgarian rose in $98 \%$ of phenyl-ethyl alcohol) as a floral odour; banana (amyl-isobutirate at $50 \%$ in dietyl-phtalate) as a food odour; musk (1:1 mixture of galaxolide and diethyl-phtalate exaltolide) as a perfume odour; and gas (mixture of 30\% mercaptan and 70\% tetrahydrothiophene) as an industrial odour. Elaboration protocols and microencapsulation were previously reported in the OLFACAT study ${ }^{(6)}$. Smell questionnaire. Participants were asked to scratch and sniff each odour and then answer three questions: 1), odour detection: did you smell any scent? (yes, no); 2), odour recognition/memory: have you ever smelt this scent? (yes, no); and 3), forcedchoice odour identification: which name defines the scent you have smelt?, only one of the four given options was correct. Firstly, the term 'normosmia' was used when a participant was able to detect, recognise (memory), or correctly identify all four tested odours. Secondly, the term 'hyposmia' was used when a participant was not able to detect, recognise (memory) or correctly identify one, two, or three tested odours and finally, the term 'anosmia' was used when a participant was unable to detect, recognise (memory), or correctly identify any of the four tested odours.

Epidemiological and health-status questionnaire. From the 12-question questionnaire, four questions were about demography. Two questions described smell self-perception: 1) how do you consider your current sense of smell? (very good, good, poor, or very poor); and 2) have you ever lost the sense of smell? (never, up to one week, and over one week). One question was on smoking status (no, ex-smoker, and current smoker) and one on exposure to toxic or noxious substances. Finally, two questions were on TBI: 1) have you ever had a severe face and/or head trauma? (yes, no); and 2) which type of accident caused the head trauma (traffic, domestic, or at work).

\section{Data management and statistical analysis}

The data-cleaning process was based on programmed queries to identify records containing inconsistent or uncertain data. The corrupt or inaccurate values identified by these queries were subsequently recorded as missing values in the data set. Only those surveys fully and consistently answered were considered for statistical analysis. Data was statistically analysed using Stata V.8 (Stata Statistical Software: Release 8.0 College Station, TX, USA: Stata Corporation 2003).

Differences in epidemiological and health-status characteristics and distribution of the survey outcomes between subjects, with or without history of head trauma, were evaluated by Chi-square or Fisher's exact test. Adjusted (multivariate) logistic regression models for anosmia and hyposmia were estimated. In order to evaluate effect modification of each independent variable due to having had a head trauma, interaction terms of each variable with such trauma were included in the model. To estimate the multivariate models for anosmia, the covariates that do not have any events (anosmia cases) in any of its categories were not included. Results from estimated models were expressed as adjusted ORs, Relative Excess Risk due to Interaction (RERI), also referred to as ICR (Interaction Contrast Ratio) and 95\% IC (Interval of Confidence). The reference category used to calculate the 


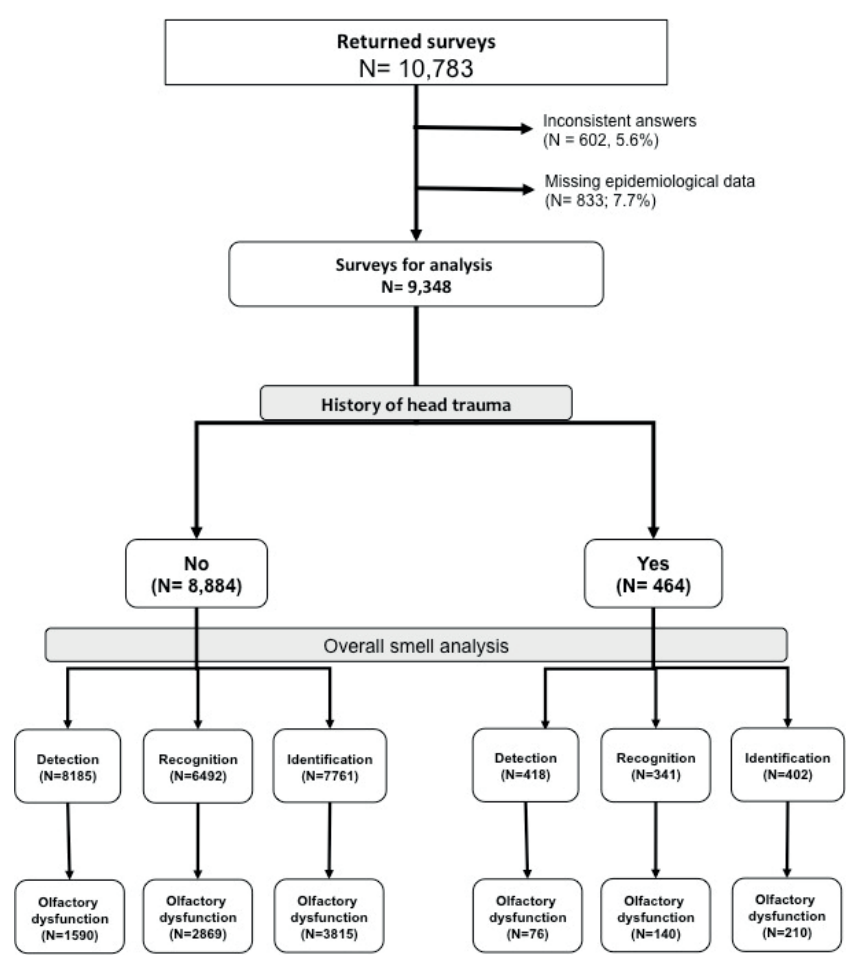

Figure 1. Flow-chart of OLFACAT survey participants with or without history of Trauma Brain Injury (TBI) and olfactory dysfunction.

OR for each level of variables measured on an ordinal scale was the immediately previous category, starting with the second. All tests were performed using a two-tailed significance level of 0.05 .

\section{Results}

Data cleaning process

From the 10,783 received surveys ( $4,1 \%$ of distributed), $13.3 \%$ (5.6\% identified as inconsistent and $7.7 \%$ with incomplete epidemiological or health-status questionnaires) were discarded. After the exclusion of inconsistent and incomplete surveys, the sample size for analysis was 9,348 questionnaires, 464 (4.9\%) of them reporting a past history of head trauma (Figure 1).

\section{Demographics}

The mean age for the surveyed population was $43.3 \pm 14.1$ years old. Mean age was similar for TBI (44.5 \pm 14.1 years-old) and nonTBI (43.3 \pm 14 years-old) subjects. Although women were predominant in the total cohort (65.7\%), the TBI group had fewer women than the non-TBI group ( $57 \%$ vs. $66 \% ; p<0.001)$. Most of the participants had a high educational level and were living in an urban area (94\%), with no statistical differences between educational levels.

Subjects in the TBI group had a higher frequency of smoking habit ( $27 \%$ vs. $21 \%$ ) and use of noxious substances ( $44 \%$ vs. $20 \%$ ) compared to the non-TBI group. Concerning smoking habit in both genders, men in the TBI group reported a higher
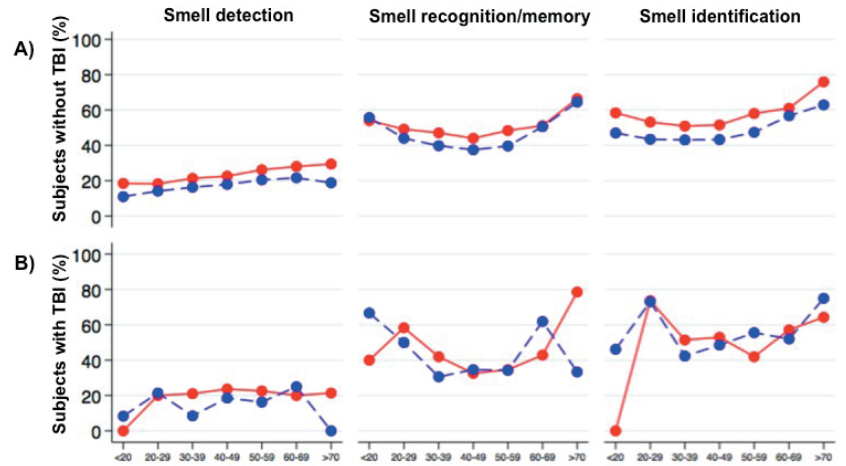

Age groups (years)

Figure 2. Smell detection, recognition/memory, and identification for participants with olfactory dysfunction according to age groups and gender (red, female; blue, male) in subjects without (A) or with (B) history of Trauma Brain Injury (TBI).

frequency of being ex-smoker or active smoker (64.5\% versus $51.5 \%, \mathrm{p}=0.008$ ).

The main causes for reported TBI were traffic (48.3\%), domestic (34.3\%), and work-related (6.5\%) accidents, $10.9 \%$ of the surveyed population reported more than one cause of head trauma. A complete description of demographic characteristics is shown in Table 1.

\section{Sense of smell}

Regardless of gender and age, more subjects in the TBI group than in the non-TBI group $(12 \%$ vs. $6 \%, \mathrm{p}<0.0001)$ self-rated their sense of smell as being poor or very poor. The frequency of loss of smell during a period of more than one week was also significantly higher in the TBI group ( $12 \%$ vs. $5 \%, \mathrm{P}<0.001)$.

In both TBI and non-TBI groups the olfactory score for normosmia and hyposmia were similarly detected, recognised and identified. Only in the anosmia of identification category, TBI subjects reported a higher frequency than that of non-TBI subjects ( $3 \%$ vs. $1 \%, p=0.003$ ). For the latter reason, the following analysis was done comparing normosmia versus olfactory dysfunction (hyposmia plus anosmia).

Overall, individual odours were more detected than recognised or correctly identified. In addition, the TBI group showed a decreases ability ( $89 \%$ vs. $92 \%, p=0.03$ ) to identify mercaptan (odour added to the gas used in cities) compared to non-TBI group. Although individual odours were always better detected, recognised, and identified by women than men in the non-TBI group, in the TBI group both men and women showed similar abilities to detect, recognize, and identify the individual odours. Table 2 shows data on the smell abilities of both TBI and non-TBI groups.

Within the population experiencing olfactory disorders and in both TBI and non-TBI groups, there was a significant and progressive age-related decline of smell detection. While smell 
Table 1. Characteristics of the OLFACAT survey population with/without history of Trauma Brain Injury (TBI).

\begin{tabular}{|c|c|c|c|c|}
\hline \multirow[t]{2}{*}{ Population characteristics } & \multicolumn{2}{|c|}{ History of TBI } & \multirow{2}{*}{$\begin{array}{c}\text { Total } \\
(\mathrm{N}=9,348)\end{array}$} & \multirow[t]{2}{*}{ p-value ${ }^{2}$} \\
\hline & Yes $(\mathrm{N}=464)$ & No $(\mathrm{N}=\mathbf{8 , 8 8 4})$ & & \\
\hline Female $^{1}$ & & & $6,137(66 \%)$ & $<0.0001$ \\
\hline Age, years (mean $\pm S D)$ & $44.5 \pm 14.1$ & $43.3 \pm 14$ & $43.3 \pm 14.1$ & 0.0580 \\
\hline \multicolumn{5}{|l|}{ Age distribution, years ${ }^{1}$} \\
\hline$<20$ & $18(4)$ & $424(5)$ & $442(5)$ & 0.3767 \\
\hline $20-29$ & $48(10)$ & $1,071(12)$ & $1,119(12)$ & \\
\hline $30-39$ & $104(22)$ & $2,051(23)$ & $2,155(23)$ & \\
\hline $40-49$ & $138(30)$ & $2,396(27)$ & $2,534(27)$ & \\
\hline $50-59$ & $88(19)$ & $1,859(21)$ & $1,947(21)$ & \\
\hline $60-69$ & $46(10)$ & $763(9)$ & $809(9)$ & \\
\hline$>70$ & $22(5)$ & $320(4)$ & $342(4)$ & \\
\hline \multicolumn{5}{|l|}{ Educational level ${ }^{1}$} \\
\hline Primary School & $2(0)$ & $31(0)$ & $33(0)$ & 0.8913 \\
\hline Secondary School & $77(17)$ & $1,409(16)$ & $1,486(16)$ & \\
\hline High School & $206(44)$ & $3,867(44)$ & $4,073(44)$ & \\
\hline University/College & $179(39)$ & $3,577(40)$ & $3,756(40)$ & \\
\hline \multicolumn{5}{|l|}{ Residency zone ${ }^{1}$} \\
\hline Rural & $9(2)$ & $157(2)$ & $166(2)$ & 0.3676 \\
\hline Semi-rural & $26(6)$ & $379(4)$ & $405(4)$ & \\
\hline City & $429(92)$ & $8,348(94)$ & $8,777(94)$ & \\
\hline \multicolumn{5}{|l|}{ Subjective description of smell ${ }^{1}$} \\
\hline Very good & $98(21)$ & $1,885(21)$ & $1,983(21)$ & 0.0001 \\
\hline Good & $310(67)$ & $6,405(72)$ & $6,715(72)$ & \\
\hline Bad / very bad & $56(12)$ & $594(6)$ & $650(7)$ & \\
\hline \multicolumn{5}{|l|}{ Loss of smell history ${ }^{1}$} \\
\hline Never & $282(61)$ & $6224(70)$ & $6506(70)$ & $<0.0001$ \\
\hline$<1$ week & $126(27)$ & $2218(25)$ & $2344(25)$ & \\
\hline$>1$ week & $56(12)$ & $442(5)$ & $498(5)$ & \\
\hline \multicolumn{5}{|l|}{ Smoking habit ${ }^{1}$} \\
\hline Non-smoker & $199(43)$ & $4,499(51)$ & $4,698(50)$ & 0.0020 \\
\hline Ex-smoker & $141(30)$ & $2,508(28)$ & $2,649(28)$ & \\
\hline Smoker & $124(27)$ & $1,877(21)$ & $2,001(21)$ & \\
\hline Exposure to noxious substances ${ }^{1}$ & $204(44)$ & $2,589(29)$ & $2,793(30)$ & $<0.0001$ \\
\hline Nasal allergy ${ }^{1}$ & $95(20)$ & $1,172(13)$ & $1,267(14)$ & $<0.0001$ \\
\hline Chronic rhinosinusitis ${ }^{1}$ & $42(9)$ & $372(4)$ & $414(4)$ & $<0.0001$ \\
\hline
\end{tabular}

TBI, traumatic brain injury; SD, standard deviation. ${ }^{1}$ number of subjects (percentage); ${ }^{2}$ Chi-squared test.

recognition and identification increased up to the fourth decade of life, it continued to plateau throughout the fifth and sixth decades and declined thereafter (Figure 2).

To further analyze the association of TBI with olfactory disorders, an adjusted logistic regression models were applied for smell detection, recognition, and identification OD. We did not find any statistical difference between the non-TBI and TBI group for all the covariables studied. In the non-TBI group, only smell detection was higher in women than in men (59\% vs. $41 \%$, $\mathrm{p}<0.0001$ ), with a higher educational level (43\% University) and the olfactory dysfunction being more frequent in the age group of 50-59 years old $(p<0.001)$. In Table 3 , the data is shown for the adjusted association between the covariables according to history of Traumatic Brain Injury (TBI) and the Relative Excess 
Table 2. Smell outcomes of the OLFACAT survey population with/without history of Trauma Brain Injury (TBI).

\begin{tabular}{|c|c|c|c|}
\hline \multirow[t]{2}{*}{ Smell outcomes } & \multicolumn{2}{|c|}{ History of TBI } & \multirow[t]{2}{*}{ p-value } \\
\hline & Yes $(\mathrm{N}=464)$ & No $(\mathrm{N}=\mathbf{8}, \mathbf{8 8 4})$ & \\
\hline \multicolumn{4}{|l|}{ Smell Detection ${ }^{1}$} \\
\hline Normosmia & $342(82)$ & $6,595(81)$ & $0.5300^{2}$ \\
\hline Olfactory disfunction & $76(18)$ & $1,590(19)$ & $0.5300^{2}$ \\
\hline Rose & $442(100)$ & $8,618(99)$ & $0.5100^{3}$ \\
\hline Musk & $379(85)$ & $7,263(84)$ & $0.5700^{2}$ \\
\hline Banana & 438 (99) & 8,470 (99) & $0.6300^{3}$ \\
\hline Mercaptan & $415(96)$ & $8,175(97)$ & $0.4500^{2}$ \\
\hline \multicolumn{4}{|l|}{ Smell Recognition/Memory ${ }^{1}$} \\
\hline Normosmia & $201(59)$ & $3,623(56)$ & $0.2600^{2}$ \\
\hline Olfactory disfunction & $140(41)$ & $2,869(44)$ & $0.2600^{2}$ \\
\hline Rose & 414 (95) & $8,076(95)$ & $0.7400^{2}$ \\
\hline Musk & $265(70)$ & $4,634(66)$ & $0.0800^{2}$ \\
\hline Banana & $386(97)$ & $7,632(96)$ & $0.3700^{2}$ \\
\hline Mercaptan & $372(96)$ & $7,230(95)$ & $0.2400^{2}$ \\
\hline \multicolumn{4}{|l|}{ Smell Identification ${ }^{1}$} \\
\hline Normosmia & $192(48)$ & $3,946(51)$ & $0.2300^{2}$ \\
\hline Olfactory disfunction & $210(52)$ & $3,815(49)$ & $0.2300^{2}$ \\
\hline Rose & $390(89)$ & 7,865 (92) & $0.0600^{2}$ \\
\hline Musk & $278(64)$ & $5,446(65)$ & $0.5500^{2}$ \\
\hline Banana & $359(87)$ & $7,241(90)$ & $0.0800^{2}$ \\
\hline Mercaptan & 377 (89) & $7,636(92)$ & $0.0300^{2}$ \\
\hline
\end{tabular}

TBI, traumatic brain injury. ${ }^{1}$ number of subjects (percentage); ${ }^{2}$ Chi-squared test; ${ }^{3}$ Fisher's exact test.

Risk due to Interaction (RERI) for smell detection, memory/recognition and identification in the TBI group.

\section{Discussion}

This post-hoc analysis of the OLFACAT survey evaluates, most specifically, the association of TBI and olfactory disorders in a general-based population. The main findings of the study were: a) self-rated description of smell impairment was higher in the TBI group (12\%); b) the fact that women have a better sense of smell than men were disregarded in the TBI group, and c) smell identification ability for mercaptan (gas) is diminished in the TBI group.

Incidence rates for TBI smell impairment in the general population are poorly reported. Our frequency for TBI in a generalbased population (4.9\%) is slightly lower that those reported in previous studies, which ranges between $5.7-45 \%{ }^{(19-21)}$. There are two large population-based studies which associate TBI with OD specifically. However, both were based only on the selfperceived OD ${ }^{(19,20)}$. Our study showed that self-rated description of smell impairment was higher in the TBI group (12\%). Nevertheless, with regards to detected, recognition and identification, the olfactory score for normosmia and hyposmia were equally in both TBI and non-TBI groups. Moreover, this could be compared to one of the biggest population-based study: "The Beaver Damm Offspring study", which could not find any association between TBI and OD in the multivariate analysis ${ }^{(21)}$. Interestingly, our study showed that being a male is not a risk factor for TBI, whilst women reported a higher prevalence of a history of TBI. This may be explained by the fact that a higher number of females responded to the survey $(65.6 \%)$. In population-based studies that is inclusive of all ages, a trimodal agespecific TBI incidence have generally been reported. Incidence peaks in early childhood, late adolescence/early adulthood, and in the elderly ${ }^{(22)}$. We observed that participants from 30 to 50 years old have the highest frequency of TBI over their life span. Moreover, the use of toxic substances and smoking habits were more frequent in the TBI cohort, which correlates with previous

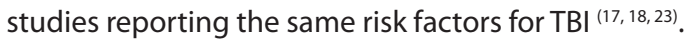

Post-traumatic olfactory dysfunction is a prevalent but under evaluated problem in patients with TBI. The evaluation of olfactory dysfunction seems largely out of focus of healthcare providers who initially deal with the assessment of TBI patients. 


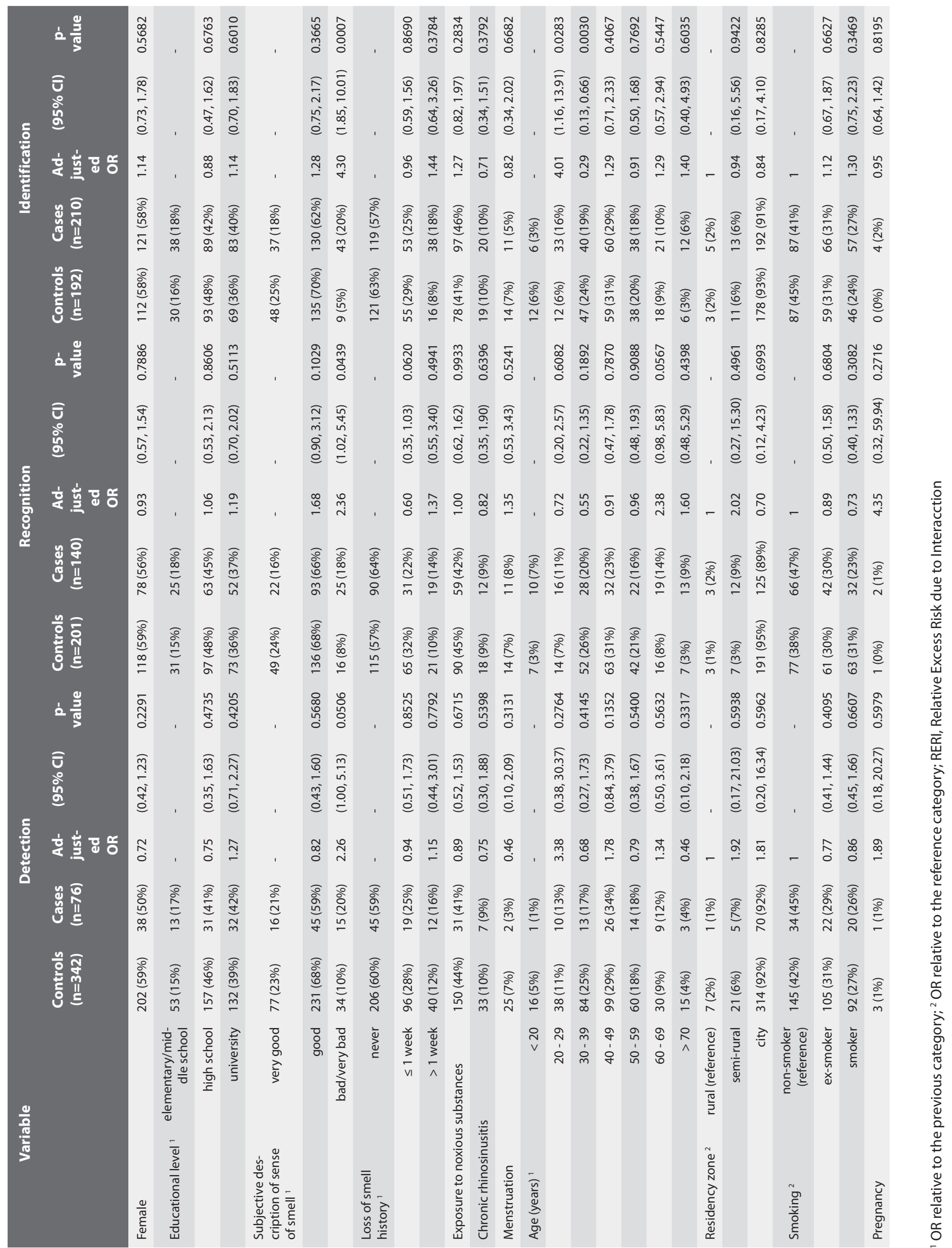


Unfortunately, during follow-up, both the healthcare provider and the patient are aware of the smell impairment and are skeptical as to how to move forward. The impact of this neurological deficit is however profound and severely affects patient's quality of life. This study demonstrated that the frequency of olfactory disorder in TBI subjects (18\%) was similar to the reported in the general population (19.4\%). Nevertheless, we observed that TBI subjects significantly reported a higher self-reported smell impairment than non-TBI subjects ( $12 \%$ versus $6 \%, p<0.001$ ). This finding is contradictory with previous published data reporting that patients with TBI do not usually self-report smell impairment, and their olfactory dysfunction can be only detected with olfactory tests ${ }^{(24,25)}$. Callahan and Hinkebein ${ }^{(24)}$ found that the more severe the trauma injury is, the more severe the olfactory impairment will be, being reflected by a low score on the University of Pennsylvania Smell Test (UPSIT). In their study, $56 \%$ of the sample population showed impaired olfaction, while $40 \%$ of them were unaware of their olfactory deficit. In our study, the similar prevalence of olfactory dysfunction, in both cohorts, could be explained by the fact that the non-TBI population encompasses people with other causes of OD. According to other studies (26,27) post infectious patients are usually middle-aged women - similar to the typical population of this study. Hence, it is highly probable that some of the non-TBI population suffer from post infectious olfactory loss, or from another cause of OD.

A decreased olfactory function with ageing in the males has been previously reported ${ }^{(6,28-30)}$. Recently Ottaviano et al. ${ }^{(31)}$ reported that odour identification significantly worsened with age and the number of drugs taken by the elderly correlated directly with a worse olfactory threshold. In our publication of the OLFACAT survey ${ }^{(6)}$, we reported a significant and progressive age-related decline of smell detection. While smell recognition and identification increased up to the fourth decade of life, it continued to plateau throughout the fifth and sixth decades and declined thereafter. Although these findings are very comparable to what we have observed in the non-TBI group, it is interesting to remark that these differences disappear in the TBI group. The findings showed that just like men, women alike have olfactory abilities that decline with ageing (Figure 2). Similar results have been reported by Doty et al. ${ }^{(9)}$ where olfactory test scores were not gender or age-related in patients with TBI olfactory dysfunction.

Smell detection, memory/recognition and identification for individual odorants or for different olfactory phenotypes (normosmia vs. olfactory disorder) show a similar frequency in both TBI and non-TBI. Specifically, when assessing mercaptan identification, we have observed a lower ability to identify mercaptan (odour added to natural gas) among subjects with TBI history. Previous studies have reported that the activities most frequently impaired by chemosensory dysfunction include identification of spoiled foods (75\%), detection of gas leaks (61\%), quality and pleasure of eating (53\%), detection of smoke (50\%), ability to prepare food (49\%), ability to correctly buy fresh food (36\%), and aptitude in using cologne or perfume (33\%) ${ }^{(32)}$. Our post-hoc analysis corroborates these findings and may explain why patients with TBI-induced smell loss are at risk of domestic accidents related to the leak of gas or smoke, as their ability (89\% vs. 92\%) to identify mercaptan (odour added to domestic gas) is decreased.

Like in all epidemiological studies, the present post-hoc analysis of the OLFACAT survey may have some limitations or weaknesses: $1 \mathrm{st}$ ) the survey population cannot be considered a random sample since there was no control over whom and how the survey was performed or whether participants were preferentially motivated to answer the survey; 2nd) the survey's data may not be fully representative of the general population since the readership survey (2003) shows that the newspaper readers belong to a higher socio-cultural class ( $85.1 \%$ middle class) and have a higher educational level (31.1\% finished secondary school) than that of the general Catalan population $(65.0 \%$ and $25.6 \%$, respectively, 2002 census); 3rd) we only used four odours to assess the olfactory status, and thus, we could not reliably state that the subjects had a real olfactory dysfunction. This is due to the fact that this test is only considered as a screening test and not a validated olfactometric test, 4 th) other studies have found different smell capacity among different ethnic groups, though the lack of ethnic/cultural diversity in our sample (mainly with European ancestors) could limit the generalization of the findings to other ethnic/cultural groups; 5 th) subjects with moderate to severe head trauma could have been more/less interested in participating in the survey leading to an over/underestimation of the frequency of smell dysfunction; and 5th) observations were based on cross-sectional data, making it impossible to disentangle true ageing effects from cohort membership; and 6th) the survey could have a positive female response bias since almost two-thirds of participants who returned the surveys were women (65.7\%).

\section{Conclusion}

In conclusion, the present study on the general population indicates that a past history of TBI is not clearly associated with olfactory disorders. Nonetheless, in those patients who do report an olfactory dysfunction after a TBI the damage, seem more related to olfactory processing deficits (odour identification).

\section{Acknowledgements}

We would like to express our gratitude and give thanks for their technical assistance and support to the OLFACAT survey to the following: Rossend Mateu, Elizabeth Vidal, Albert Casacuberta, Carles M Pelejero, Montserrat Ribas, Elizabet Ribot, Josep Vivas, and Montserrat Calzada from Antonio Puig SA; Nadine Jaouani and Philippe Ughetto from ARCADE Europe; Francesc Aldea 
from AstraZeneca; Josep Garcia-Miquel, Àngels Gallardo, Víctor Blanes, Joan C Brenchat, Augusto Bueno, Bernat Gasulla, Xavier Martínez-Chico, and Antoni Pelegrin from El Periódico de Catalunya; JM López-Zurita from ENAGAS; Juan Solís, Sebastià Gumà, and Maria C. González from Fundació Gas Natural; and Àngels Pont from VoxPublica/GESOP. Furthermore, we also thank for their collaboration in the OLFACAT survey to: Tomàs Molina from Televisió de Catalunya; Núria Cots, Sergi Paricio, and Oriol Puig from Servei Meteorològic de Catalunya; Professor Jordina Belmonte from Universitat Autònoma de Barcelona (UAB); Professor Joan R Morante from Universitat de Barcelona (UB) and Professor Joan M Canals from Universitat Rovira i Virgili (URV) de Tarragona.

This study was partially supported by Antonio Puig SA, Myrurgia, Fundació Gas Natural and ENAGAS for producing the odorants; ARCADE Europe for microencapsulating the odorants; El Periódico de Catalunya for printing, distributing, and collecting the surveys as well as for publishing a special issue on the sense of smell; AstraZeneca for supporting the investigator meetings; and Voxpublica (GESOP) for performing the survey's optical readings and collecting the final data of the OLFACAT study. Some of the above study sponsors participated in the design of the survey (Antonio Puig, Fundació Gas Natural and ARCADE Europe) and in the collection of survey data (VoxPublica/GESOP). However, none of the sponsors participated in the analysis and interpretation of data, writing of the report and the decision to submit the report for publication.

\section{Authorship contribution}

$\mathrm{CL}$ has contributed with literature search, acquisition of data, analysis and interpretation of data, and writing the manuscript. $\mathrm{JM}, \mathrm{CM}$, and IA have contributed with the conception and design of the study, interpretation of data, drafting the manuscript, and approved the final version. LQ has contributed with the study design, acquisition of data, statistical analysis, data interpretation, and drafting the manuscript, while approving the final version. AV and CP have contributed with the study conception and with a critical reading of the manuscript, while approving the final version. All authors had full access to the study data, including statistical reports and tables.

\section{Conflict of interest}

In relation to the content of this manuscript, none of the authors have competing financial interests.

\section{References}

1. Ghajar J. Traumatic brain injury. Lancet. 2000;356(9233): 923-9.

2. Maas AIR, Stocchetti N, Bullock R. Moderate and severe traumatic brain injury in adults. Lancet Neurol. 2008;7(8):728-41.

3. Tagliaferri F, Compagnone C, Korsic M, Servadei F, Kraus J. A systematic review of brain injury epidemiology in Europe. Acta Neurochir (Wien). 2006;148(3):255-68.

4. Thornhill S, Teasdale GM, Murray GD, McEwen J, Roy CW, Penny KI. Disability in young people and adults one year after head injury: prospective cohort study. BMJ. 2000;7;320(7250):1631-5.

5. Brämerson A, Johansson L, Ek L, Nordin S, Bende M. Prevalence of olfactory dysfunction: the Skövde population-based study. Laryngoscope. 2004;114(4):733-7.

6. Mullol J, Alobid I, Mariño-Sánchez F, Quintó $L$, de Haro J, Bernal-Sprekelsen $M$, et al. Furthering the understanding of olfaction, prevalence of loss of smell and risk factors: a population-based survey (OLFACAT study). BMJ Open. 2012;2(6):e001256.

7. Koskinen S, Alaranta H. Traumatic brain injury in Finland 1991-2005: a nationwide register study of hospitalized and fatal TBI. Brain Inj. 2008;22(3):205-14.

8. Haxel BR, Grant L, Mackay-Sim A. Olfactory dysfunction after head injury. J Head Trauma Rehabil. 2008;23(6):407-13.

9. Doty RL, Yousem DM, Pham LT, Kreshak AA, Geckle R, Lee WW. Olfactory dysfunction in patients with head trauma. Arch Neurol. 1997;54(9):1131-40.

10. Drummond M, Douglas J, Olver J. "I really hope it comes back" -Olfactory impairment following Traumatic Brain Injury: a longitudinal study. Neurorehabilitation. 2017;41(1):241-8.

11. Schofield PW, Moore TM, Gardner A. Traumatic Brain Injury and olfaction: a systematic review. Front Neurol [Internet]. 2014;5:5

12. Costanzo RM, Miwa T. Posttraumatic olfactory loss. Adv Otorhinolaryngol. 2006;63:99-107.

13. Fortin A, Lefebvre MB, Ptito M. Traumatic brain injury and olfactory deficits: the tale of two smell tests! Brain Inj. 2010;24(1):27-33.

14. de Kruijk JR, Leffers P, Menheere PPCA, Meerhoff S, Rutten J, Twijnstra A. Olfactory function after mild traumatic brain injury. Brain Inj. 2003;17(1):73-8.

15. Roozenbeek B, Maas AIR, Menon DK. Changing patterns in the epidemiology of traumatic brain injury. Nat Rev Neurol. 2013;9(4):231-6.

16. Boswell JE, McErlean M, Verdile VP. Prevalence of traumatic brain injury in an ED population. Am J Emerg Med 2002;20(3):177-80.

17. Frost RB, Farrer TJ, Primosch $M$, Hedges DW. Prevalence of traumatic brain injury in the general adult population: a meta-analysis. Neuroepidemiology. 2013;40(3):154-9.

18. Bombardier $\mathrm{CH}$, Rimmele $\mathrm{CT}$, Zintel $\mathrm{H}$. The magnitude and correlates of alcohol and drug use before traumatic brain injury. Arch Phys Med Rehabil. 2002; 83(12):1765-73

19. Sumner, D. Post-traumatic anosmia. Brain. 1964;87:107-20

20. Bainbridge, K.E., D. Byrd-Clark, and
D. Leopold. Factors Associated With Phantom Odor Perception Among US Adults: Findings From the National Health and Nutrition Examination Survey. JAMA Otolaryngol Head Neck Surg. 2018;144(9): 807-814.

21. Schubert CR, Cruickshanks KJ, Fischer ME, et al., Olfactory impairment in an adult population: the Beaver Dam Offspring Study. Chem Senses. 2012;37(4): 325-34.

22. Bruns J. and Hauser WA. The epidemiology of traumatic brain injury: a review. Epilepsia. 2003:44(s10):2-10.

23. Dewan MC, Rattani A, Gupta S, Baticulon RE, Hung $Y-C$, Punchak $M$, et al. Estimating the global incidence of traumatic brain injury. J Neurosurg. 2018

24. Callahan CD, Hinkebein JH. Assessment of anosmia after traumatic brain injury: performance characteristics of the University of Pennsylvania Smell Identification Test. J Head Trauma Rehabil. 2002;17(3):251-6.

25. Gudziol V, Hoenck I, Landis B, Podlesek D, Bayn M, Hummel T. The impact and prospect of traumatic brain injury on olfactory function: a cross-sectional and prospective study. Eur Arch Oto-Rhino-Laryngol. 2014;271(6):1533-40.

26. Fonteyn S, Huart C, Deggouj N, et al. Non-sinonasal-related olfactory dysfunction: A cohort of 496 patients. Eur Ann Otorhinolaryngol Head Neck Dis. 2014;131(2):87-91.

27. Brämerson A, Nordin S, Bende M. Clinical experience with patients with olfactory complaints, and their quality of life. Acta Otolaryngol. 2007;127(2):167-74. 
28. Hoffman HJ, Ishii EK, MacTurk RH. Agerelated changes in the prevalence of smell/ taste problems among the United States adult population. Results of the 1994 dis ability supplement to the National Health Interview Survey (NHIS). Ann N Y Acad Sci. 1998;855:716-22.

29. Hummel T, Kobal G, Gudziol H, Mackay-Sim A. Normative data for the "Sniffin' Sticks" including tests of odor identification, odor discrimination, and olfactory thresholds: an upgrade based on a group of more than 3,000 subjects. Eur Arch Oto-RhinoLaryngol. 2007;264(3):237-43.

30. Hummel T, Whitcroft K.L., Andrews P., et al. Position paper on olfactory dysfunction. Rhinology. 2017;54(Suppl 26):1-30.

31. Ottaviano G, Savietto E, Scarpa B, et al Influence of number of drugs on olfaction in the elderly. Rhinology. 2018;56(4):351-7
32. Miwa T, Furukawa M, Tsukatani T, Costanzo RM, DiNardo LJ, Reiter ER. Impact of olfactory impairment on quality of life and disability. Arch Otolaryngol Head Neck Surg. 2001;127(5):497-503.
Joaquim Mullol, MD, PhD Immunoal.lèrgia Respiratòria Clínica i

Experimental, IDIBAPS

Unitat de Rinologia i Clínica de

I'Olfacte

Servei d'Otorinolaringologia

Hospital Clínic i Universitari

Villarroel 170

08036 Barcelona

Catalonia, Spain

Tel: +34932279872

Fax: +34 932279813

E-mail:jmullol@clinic.cat 